\title{
Presynaptic and Postsynaptic Amplifications of Neuropathic Pain in the Anterior Cingulate Cortex
}

\author{
Hui Xu, ${ }^{\star}$ Long-Jun Wu, ${ }^{\star}$ Hansen Wang, ${ }^{\star}$ Xuehan Zhang, Kunjumon I. Vadakkan, Susan S. Kim, Hendrik W. Steenland, \\ and Min Zhuo \\ Department of Physiology, Faculty of Medicine, University of Toronto Centre for the Study of Pain, Toronto, Ontario, Canada M5S1A8
}

\begin{abstract}
Neuropathic pain is caused by a primary lesion or dysfunction in the nervous system. Investigations have mainly focused on the spinal mechanisms of neuropathic pain, and less is known about cortical changes in neuropathic pain. Here, we report that peripheral nerve injury triggered long-term changes in excitatory synaptic transmission in layer II/III neurons within the anterior cingulate cortex (ACC). Both the presynaptic release probability of glutamate and postsynaptic glutamate AMPA receptor-mediated responses were enhanced after injury using the mouse peripheral nerve injury model. Western blot showed upregulated phosphorylation of GluR1 in the ACC after nerve injury. Finally, we found that both presynaptic and postsynaptic changes after nerve injury were absent in genetic mice lacking calcium-stimulated adenylyl cyclase $1(\mathrm{AC} 1)$. Our studies therefore provide direct integrative evidence for both long-term presynaptic and postsynaptic changes in cortical synapses after nerve injury, and that $\mathrm{ACl}$ is critical for such long-term changes. $\mathrm{ACl}$ thus may serve as a potential therapeutic target for treating neuropathic pain.
\end{abstract}

Key words: anterior cingulate cortex; presynaptic release; adenylyl cyclase; AMPA receptor; mice; neuropathic pain

\section{Introduction}

Long-term potentiation (LTP) is believed to be the key mechanism for storing sensory information in the brain (Kaas, 1991; Bliss and Collingridge, 1993; Buonomano and Merzenich, 1998; Kandel, 2001; LeDoux, 2003). For example, noxious or painful foot shocks trigger long-term changes of excitatory glutamate transmission within the amygdala (Davis et al., 1994; Malenka and Nicoll, 1997; McKernan and Shinnick-Gallagher, 1997; Blair et al., 2001; Tsvetkov et al., 2002; Rumpel et al., 2005). It is believed that such changes in synaptic transmission play key roles in fear memory. Similarities between persistent pain and memory have been recently reported (Woolf and Salter, 2000; Wei et al., 2001, 2002; Sandkühler, 2007; Zhuo, 2007). Long-term changes in synaptic transmission, occurring in sensory synapses located along the somatosensory pathway or pain-processing brain regions, contribute to chronic inflammatory and neuropathic pain (Woolf and Salter, 2000; Wei et al., 2001; Sandkühler, 2007; Zhuo, 2007).

Most studies on sensory-related synapses have focused on long-term changes at the periphery and spinal dorsal horn neu-

\footnotetext{
Received Feb. 21, 2008; revised June 6, 2008; accepted June 9, 2008.

This work was supported by grants from the EJLB-Canadian Institutes of Health Research (CIHR) Michael Smith Chair in Neurosciences and Mental Health, Canada Research Chair, CIHR Grants CIHR84256 and CIHR66975, and National Institutes of Health-National Institute of Neurological Disorders and Stroke Grant NS42722 to M.Z. L.-J.W. was supported by postdoctoral fellowships from the CIHR and Fragile X Foundation of Canada. We would also like to thank Drs. Louis Muglia and Daniel R. Storm for providing $\mathrm{AC}^{-1-}$ mice.

${ }^{*}$ H.X., L.-J.W., and H.W. contributed equally to this work.

Correspondence should be addressed to Dr. Min Zhuo, Department of Physiology, University of Toronto, Faculty of Medicine, Room 3342, Medical Sciences Building, 1 King's College Circle, Toronto, Ontario, Canada M5S1A8. E-mail:min.zhuo@utoronto.ca.

DOI:10.1523/JNEUROSCI.1812-08.2008

Copyright $\odot 2008$ Society for Neuroscience $\quad$ 0270-6474/08/287445-09\$15.00/0
}

rons (Boucher and McMahon, 2001; Coull et al., 2003, 2005; Ikeda et al., 2003; Kohno et al., 2003; Balasubramanyan et al., 2006; Ikeda et al., 2006; Nassar et al., 2006), and few studies have examined pain-related cortical synapses in neuropathic pain status. Cumulative evidence from both human and animal studies demonstrates that forebrain neurons, including neurons in the anterior cingulate cortex (ACC) and insular cortex, are important for pain-related perception and chronic pain. Local lesions of the medial frontal cortex, including the ACC, reduced acute nociceptive responses, injury-related aversive behaviors, and chronic pain in patients (Lee et al., 1999; Johansen et al., 2001; Zhuo, 2006). Electrophysiological recordings from ACC neurons showed that ACC cells responded to peripheral noxious stimuli (Sikes and Vogt, 1992; Yamamura et al., 1996; Koyama et al., 1998; Hutchison et al., 1999). Neuroimaging studies in humans have further confirmed these observations and showed that the ACC, together with other cortical structures, were activated by acute noxious stimuli, psychological pain, and social pain (Talbot et al., 1991; Rainville et al., 1997; Casey, 1999; Koyama et al., 2000; Rainville et al., 2001; Eisenberger et al., 2003). Molecular and cellular mechanisms for long-term changes in ACC neurons, however, receive few attentions. For example, in the case of neuropathic pain, it is unknown whether excitatory synaptic transmission undergoes plastic changes. If so, are there presynaptic enhancements of glutamate release or postsynaptic glutamate receptor-mediated responses? Finally, what is the key signaling protein or messenger for triggering such long-term plastic changes in the cortex?

In the present study, we used integrative methods, including electrophysiological, pharmacological, biochemical, behavioral, and genetic approaches to address these questions. We used brain slice preparation to investigate excitatory transmission in the 
ACC after nerve injury in a mouse model of neuropathic pain (Vadakkan et al., 2005). We found that nerve injury triggered both presynaptic and postsynaptic changes in excitatory synapses within the ACC. In genetic knock-out of calcium-stimulated adenylyl cyclase subtype $1\left(A C 1^{-/-}\right)$mice, we found that both presynaptic and postsynaptic changes were abolished, consistent with the decrease of allodynia in $\mathrm{ACl}^{-1-}$ mice in behavioral studies.

\section{Materials and Methods}

Animal surgery. Adult (6-8 weeks old) male C57BL/6 mice were purchased from Charles River. Mice were maintained on a $12 \mathrm{~h}$ light/dark cycle. Food and water were provided ad libitum. $A C 1^{-1-}$ mice were bred for several generations on a C57BL/6 background. Experiments were performed under protocols approved by the University of Toronto Animal Care Committee. The $\mathrm{ACl}^{-1-}$ male mice at the same age as C57BL/6 male mice were used in this study. A model of neuropathic pain was induced by the ligation of the common peroneal nerve (CPN) as described previously (Vadakkan et al., 2005). Briefly, mice were anesthetized by intraperitoneal injection of a mixture saline of ketamine $(0.16 \mathrm{mg} / \mathrm{kg}$; Bimeda-MTC) and xylazine (0.01 $\mathrm{mg} / \mathrm{kg}$; Bayer). The CPN was visible between anterior and posterior groups of muscles running almost transversely. The left CPN was ligated with chromic gut suture 5-0 (Ethicon) slowly until contraction of the dorsiflexors of the foot was visible as twitching of the digits. The mechanical allodynia was tested on postsurgical day 7 , and the mice were used for electrophysiological studies on postsurgical days 7-14 (Fig. 1A).

Whole-cell patch-clamp recordings. Coronal brain slices $(300 \mu \mathrm{m})$ at the level of the ACC were prepared using standard methods ( $\mathrm{Wu}$ et al., 2005; Zhao et al., 2006). Slices were transferred to submerged recovery chamber with oxygenated $\left(95 \% \mathrm{O}_{2}\right.$ and $\left.5 \% \mathrm{CO}_{2}\right)$ artificial CSF containing (in mM) $124 \mathrm{NaCl}, 2.5 \mathrm{KCl}, 2 \mathrm{CaCl}_{2}, 1$ $\mathrm{MgSO}_{4}, 25 \mathrm{NaHCO}_{3}, 1 \mathrm{NaH}_{2} \mathrm{PO}_{4}$, and 10 glucose at room temperature for at least $1 \mathrm{~h}$. Experiments were performed in a recording chamber on the stage of a BX51W1 microscope equipped with infrared differential interference contrast optics for visualization. EPSCs were recorded from layer II/III neurons with an Axon 200B amplifier (Molecular Devices), and the stimulations were delivered by a bipolar tungsten stimulating electrode placed in layer $\mathrm{V}$ of the ACC. AMPA receptor-mediated EPSCs were induced by repetitive stimulations at $0.05 \mathrm{~Hz}$, and neurons were voltage clamped at -70 $\mathrm{mV}$ in the presence of AP5 $(50 \mu \mathrm{M})$. The recording pipettes (3-5 M $\Omega$ ) were filled with a solution containing (in $\mathrm{mM}$ ) $145 \mathrm{~K}$-gluconate, $5 \mathrm{NaCl}$, $1 \mathrm{MgCl}_{2}, 0.2$ EGTA, 10 HEPES, $2 \mathrm{Mg}$-ATP, $0.1 \mathrm{Na}_{3}$-GTP, and 10 phosphocreatine disodium (adjusted to $\mathrm{pH} 7.2$ with $\mathrm{KOH}$ ). The internal solution (in $\mathrm{mm}$ ) 140 cesium methanesulfonate, $5 \mathrm{NaCl}, 0.5 \mathrm{EGTA}, 10$ HEPES, 2 MgATP, $0.1 \mathrm{Na}_{3}$ GTP, 0.1 spermine, 2 QX-314 bromide, and 10 phosphocreatine disodium (adjusted to $\mathrm{pH} 7.2$ with $\mathrm{CsOH}$ ) was used in the rectification of AMPA receptor-mediated transmission experiment. For calculating the rectification of AMPA receptor-mediated EPSCs, we recorded the currents at holding potentials of $-65,-5$, and $+35 \mathrm{mV}$. Then the ratio of peak EPSC amplitude at negative $(-65 \mathrm{mV})$ and positive $(+35 \mathrm{mV})$ holding potentials was used as a measure of the rectification index. For miniature EPSC (mEPSC) recording, $0.5 \mu \mathrm{M}$ TTX was neurons).
B

\section{ACC Layer II-III}

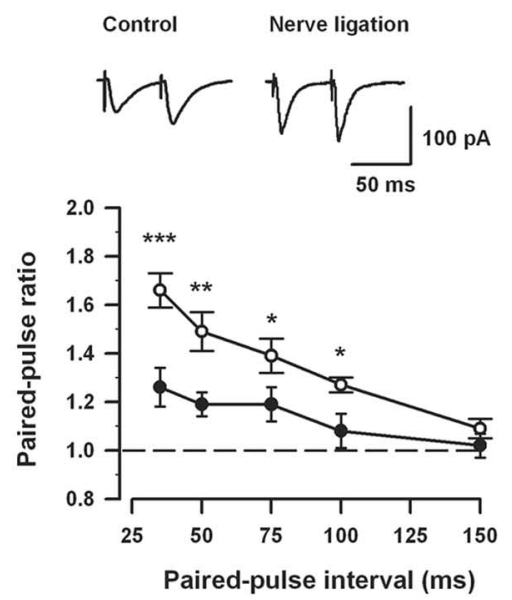

D

Motor cortex

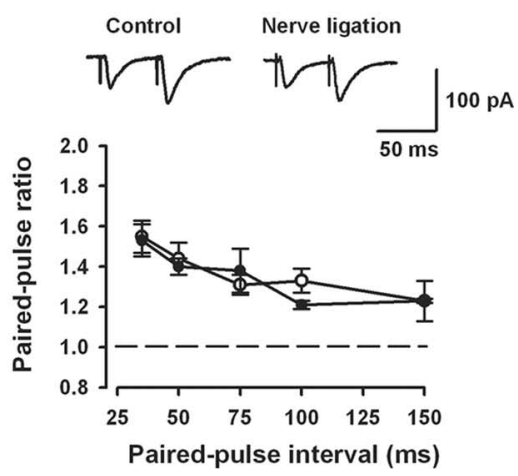

Figure 1. Increased synaptic transmission in layer II/III in the ACC after peripheral nerve ligation. $A$, Synaptic input- output curves in slices from control ( $n=6$ neurons) and nerve-ligated ( $n=7$ neurons) mice. ${ }^{*} p<0.05$ and ${ }^{* *} p<0.01$ compared with the control group. Open circles, Neurons from control mice; filled circles, neurons from mice with nerve ligation. $\boldsymbol{B}$, Representative traces with an interval of $50 \mathrm{~ms}$ recorded in layer II/III of the ACC. Paired-pulse ratio (the ratio of EPSC2/EPSC1) was 作 C, PPF in layer V of the ACC from control and nerve-ligated mice. Open circles, Neurons from control mice ( $n=9$ neurons); filled circles, neurons from mice with nerve ligation ( $n=15$ neurons). $\boldsymbol{D}$, PPF in motor cortex neurons from control and nerve-ligated mice. Open circles, Neurons from control mice ( $n=5$ neurons); filled circles, neurons from mice with nerve ligation $(n=5$

added in the perfusion solution. Picrotoxin $(100 \mu \mathrm{M})$ was always present to block $\mathrm{GABA}_{\mathrm{A}}$ receptor-mediated inhibitory synaptic currents in all experiments. Access resistance was 15-30 M $\Omega$ and monitored throughout the experiment. Data were discarded if access resistance changed $>15 \%$ during an experiment. Data were filtered at $1 \mathrm{kHz}$, and digitized at $10 \mathrm{kHz}$.

Western blot. Bilateral ACCs from the mice were dissected and homogenized in lysis buffer containing $10 \mathrm{~mm}$ Tris- $\mathrm{HCl}, \mathrm{pH}$ 7.4, 2 mм EDTA, $1 \%$ SDS, $1 \times$ protease inhibitor mixture (Sigma), and $1 \times$ phosphatase inhibitor mixture I and II (Sigma). The analysis was performed according to the procedures as reported previously (Wang et al., 2007). Briefly, the protein samples were quantified by Bradford assay. Electrophoresis of equal amounts of total protein was performed on SDS-polyacrylamide gels. Separated proteins were transferred overnight to polyvinylidene fluoride membranes at $4^{\circ} \mathrm{C}$. Membranes were probed with 1:3000 dilution of anti-GluR1 (Millipore), anti-GluR2/3 (Millipore Bioscience Research Reagents), and 1:1000 dilution of anti-phospho-GluR1 Ser845 (Millipore). The membranes were incubated in the appropriate horse- 
radish peroxidase-coupled secondary antibody diluted at 1:3000 for $1 \mathrm{~h}$ followed by enhanced chemiluminescence detection of the proteins with Western Lightning Chemiluminescence Reagent Plus (PerkinElmer Life Sciences). To ensure equal loading, membranes were also probed with 1:3000 dilution of anti-actin antibody (Sigma). The density of immunoblots of proteins was quantified with NIH ImageJ software.

Preparation of cytosolic and membrane fractions. The cytosolic and membrane fractions were prepared as described previously (Morozov et al., 2003) 1 week after nerve ligation. Briefly, the ACC samples were homogenized in the lysis buffer (10 mm Tris, $\mathrm{pH} 7.4,300 \mathrm{~mm}$ sucrose, and $1 \mathrm{~mm}$ EDTA) containing protease inhibitor mixture and then centrifuged at $8000 \times g$ for $5 \mathrm{~min}$. The pellet (P1) containing nuclei and debris was discarded. The supernatant (S1) was then centrifuged at $40,000 \times g$ for 30 min to obtain the cytosol extract in the supernatant (S2) and crude membrane in the pellet (P2). This pellet (P2), which includes cellular membranes, was resuspended in lysis buffer with protease inhibitor mixture. Protein concentrations were determined using Bio-Rad protein reagent. The expression of GluR1 and GluR2/3 subunits was characterized by Western blot. The expression of actin and cadherin was detected for equal loading of cytosolic and membrane extracts, respectively.

Cannulation surgery and microinjection. Mice were anesthetized with isoflurane (1-3\%, as needed) inhalation with $30 \%$ oxygen balanced with nitrogen. The scalp was shaved and then cleaned with iodine (Triadine) and alcohol. The head of the mouse was fixed into a stereotaxic adapter mounted on a stereotaxic frame (Kopf model 962) and lubricant (Artificial Tears) was applied to the eyes. An incision was made over the skull and the surface was exposed. Two small holes were drilled above the ACC, and the dura was gently reflected. Guide cannulas were placed so that the final coordinates of the microinjection would be $0.7 \mathrm{~mm}$ anterior to bregma, $0.3 \mathrm{~mm}$ lateral to the midline, and $1.75 \mathrm{~mm}$ ventral to the surface of the skull (Wei et al., 2002). For microinjection, mice were restrained in a plastic cone (Braintree Scientific), and a small hole was cut in the plastic overlying the microinjection guides. The dummy cannulas were removed, and the microinjection cannula was inserted into the guide. A 30 gauge injection cannula was used, which was $0.8 \mathrm{~mm}$ lower than the guide. Microinjection was conducted using a motorized syringe pump (Razel Scientific Instruments) and a Hamilton syringe. CNQX (1 $\mathrm{mm})$ dissolved in saline was delivered to left and right ACC $(500 \mathrm{~nL}$ in 1 min) through the cannula. The volume delivered was confirmed by watching the movement of the meniscus down a length of calibrated polyethylene (PE10) tubing. After delivery to each side of the brain, the injection cannula was left in place for $1 \mathrm{~min}$ to help prevent any solution from flowing back up the guide. The cannula was then retracted and inserted into the opposite side of the brain. After microinjection, the animals were immediately delivered to a clear plastic cylinder for behavioral observation.

Mechanical allodynia test. Mice were placed in a round container and allowed to acclimate for 30 min before testing. Mechanical allodynia was assessed based on the responsiveness of the hindpaw to the application of von Frey filaments (Stoelting) to the point of bending. Positive responses include licking, biting, and sudden withdrawal of the hindpaw. Experiments were performed to characterize the threshold stimulus. Mechanical pressure from a 1.65 filament (force, $0.008 \mathrm{~g}$ ) was found to be innocuous in normal mice. This filament was then used to test the mechanical allodynia after nerve ligation. Mechanical allodynia was tested five times with an intertrial interval of $10 \mathrm{~min}$. Animals were then permitted a rest period for $20 \mathrm{~min}$, after which mechanical allodynia was again tested. A total of three mechanical allodynia test sets were performed as baseline (day 5), and two test sets (day 6) were performed after drug infusion. The results are expressed as a percentage of positive responses.

Data analysis. Results are presented as means \pm SEM. Statistical comparisons were performed using two-way ANOVA and the Student's $t$ test. Analysis of mEPSCs was performed with cumulative probability plots. The level of significance was set at $p<0.05$.

\section{Results}

Enhanced excitatory synaptic transmission

To explore whether there is any change in basal synaptic transmission within the ACC after nerve injury, we recorded AMPA receptor-mediated EPSCs in pyramidal neurons in the layer II/III of the ACC in mice with peripheral nerve ligation (Vadakkan et al., 2005). Recorded neurons were identified as pyramidal neurons based on their ability to show spike frequency adaptation in response to the prolonged depolarizing-current injection (Tsvetkov et al., 2004). Input (stimulation intensity)-output (EPSC amplitude) curve of AMPA receptor-mediated current was significantly shifted to the left after peripheral nerve injury ( $n=7$ neurons/5 mice), compared with that in control group $(n=6$ neurons/4 mice, twoway ANOVA, $p<0.05$ ) (Fig. $1 A$ ). These results suggest that excitatory synaptic transmission was increased in the ACC after peripheral nerve injury.

\section{Altered paired-pulse facilitation}

To examine whether presynaptic or postsynaptic mechanisms mediate the enhanced excitatory synaptic transmission in the ACC in mice with neuropathic pain, paired-pulse facilitation (PPF) was examined in ACC neurons in the present study. PPF is a transient form of plasticity commonly used as a measure of presynaptic function, in which the response to the second stimulus is enhanced as a result of residual calcium in the presynaptic terminal after the first stimulus (Foster and McNaughton, 1991). In control mice, PPF was observed at different stimulus intervals of $35,50,75,100$, and $150 \mathrm{~ms}$. After nerve ligation, there was a significant reduction in PPF in ACC neurons $(n=19$ neurons/7 mice) compared with those from control mice ( $n=17$ neurons/7 mice, two-way ANOVA, $p<0.05$ ) (Fig. $1 B$ ). To test whether the change of PPF is region specific for the ACC after nerve injury, we tested the ratios of PPF layer V in the ACC and in the motor cortex. The result showed that there was no difference in the ratio of PPF either in layer V of the ACC (nerve-ligated group: $n=15 / 4$ mice; control group: $n=9$ neurons/5 mice; two-way ANOVA, $p>0.05$ ) (Fig. 1C) or in the motor cortex between nerve-ligated $(n=5)$ and control $(n=5$, two-way ANOVA, $p>0.05)($ Fig. $1 D)$ groups. These results indicate that presynaptic enhancement of the excitatory synaptic transmission selectively occurs in the layer II/III of the ACC after nerve injury.

\section{Enhanced presynaptic transmitter release probability}

To further determine whether decreased PPF in the ACC after peripheral nerve injury might be attributable to the increased presynaptic transmitter release probability, we recorded AMPA receptor-mediated mEPSCs in ACC neurons in the presence of $0.5 \mu \mathrm{M}$ tetrodotoxin. After peripheral nerve injury, there was an obvious increase of mEPSC frequency in ACC neurons compared with that of control group (control: $0.9 \pm 0.1 \mathrm{~Hz}, n=9$ neurons/ 5 mice; nerve ligation: $2.3 \pm 0.5 \mathrm{~Hz}, n=13$ neurons $/ 5$ mice; $p<0.05$ ) (Fig. $2 B, C$ ). Furthermore, there was significant difference in the amplitude of mEPSCs between the two groups (control: $11.2 \pm 0.8 \mathrm{pA}, n=9$ neurons $/ 5$ mice; nerve ligation: $14.1 \pm$ $0.5 \mathrm{pA}, n=13$ neurons $/ 5$ mice; $p<0.01$ ) (Fig. $2 B, C$ ).

We further tested the blocking rate of an irreversible NMDA receptor blocker, (+)-5-methyl-10,11-dihydro-5H-dibenzo$[a, d]$ cyclohepten-5,10-imine maleate (MK-801), in both control mice and mice with neuropathic pain. The blocking rate of NMDA receptor-mediated synaptic current by MK-801 is used to estimate the transmitter-release probability (Hessler et al., 1993; Weisskopf and Nicoll, 1995). At a holding potential of $-10 \mathrm{mV}$, NMDA receptor-mediated EPSCs were recorded in the presence of CNQX $(20 \mu \mathrm{M})$ and picrotoxin $(100 \mu \mathrm{M})$ at $0.1 \mathrm{~Hz}$. MK-801 $(35 \mu \mathrm{M})$ was perfused after obtaining stable NMDA receptormediated EPSCs. Our results showed that MK-801 progressively blocked NMDA receptor-mediated EPSCs and completely inhib- 
A

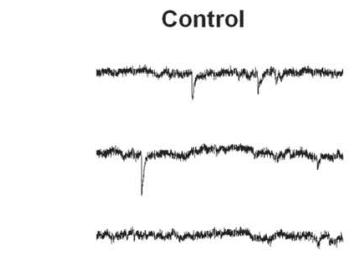

B

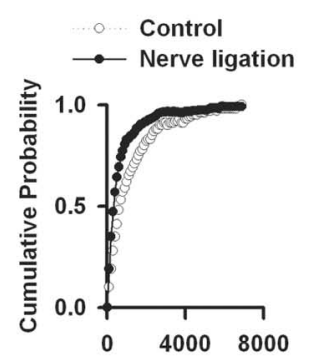

Inter-event Interval (ms)

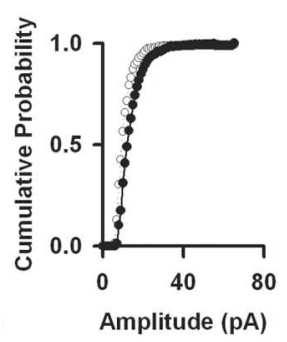

C

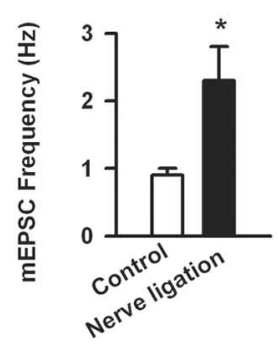

Figure 2. $\mathrm{mEPSC}$ recorded in the ACC in mice after peripheral nerve ligation. $\boldsymbol{A}$, Representative $\mathrm{mEPSC}$ recorded in the ACC neuron in slices from control mice (left) and mice with nerve ligation (right) at a holding potential of $-70 \mathrm{mV}$. B, Cumulative interevent interval (left) and amplitude (right) histograms of mEPSCs recorded in slices from control mice (open circles; $n=$ 9 neurons) and mice with nerve ligation (filled circles; $n=13$ neurons). C, Summary plots of $\mathrm{mEPSC}$ data. Averaged values of mEPSC parameters: mean peak frequency (left) and amplitude (right). ${ }^{*} p<0.05 ;{ }^{* *} p<0.01$.

ited the current in $25 \mathrm{~min}$ (Fig. $3 A, B$ ). The blocking rate of the inhibition of NMDA receptor-mediated EPSCs by MK-801 in mice with neuropathic pain was considerably faster than that of the control mice (Fig. $3 A, B$ ). We tested the time required for peak amplitude of NMDA receptor-mediated EPSCs to decay to $50 \%$ of initial value in the presence of MK- 801 . Significantly faster decay time was observed in mice with nerve ligation (5.8 \pm $0.5 \mathrm{~min} ; n=8$ neurons $/ 6$ mice $)$ than control mice $(7.5 \pm 0.6 \mathrm{~min}$; $n=7$ neurons $/ 2$ mice; $p<0.05$ ) (Fig. $3 C$ ). Together, these results indicate that the enhanced excitatory synaptic transmission in the ACC after nerve injury is attributable to an increase in probability of presynaptic neurotransmitter release and an increase of postsynaptic responsiveness as well.

\section{GluR1 modulation}

AMPA receptors are heteromultimers assembled from GluR1, GluR2, GluR3, and GluR4 subunits (Sommer et al., 1991; Hollmann and Heinemann, 1994). To further determine the role of AMPA receptors in the enhanced synaptic transmission in the ACC after nerve injury, we examined the expression levels of

A

Control Nerve ligation
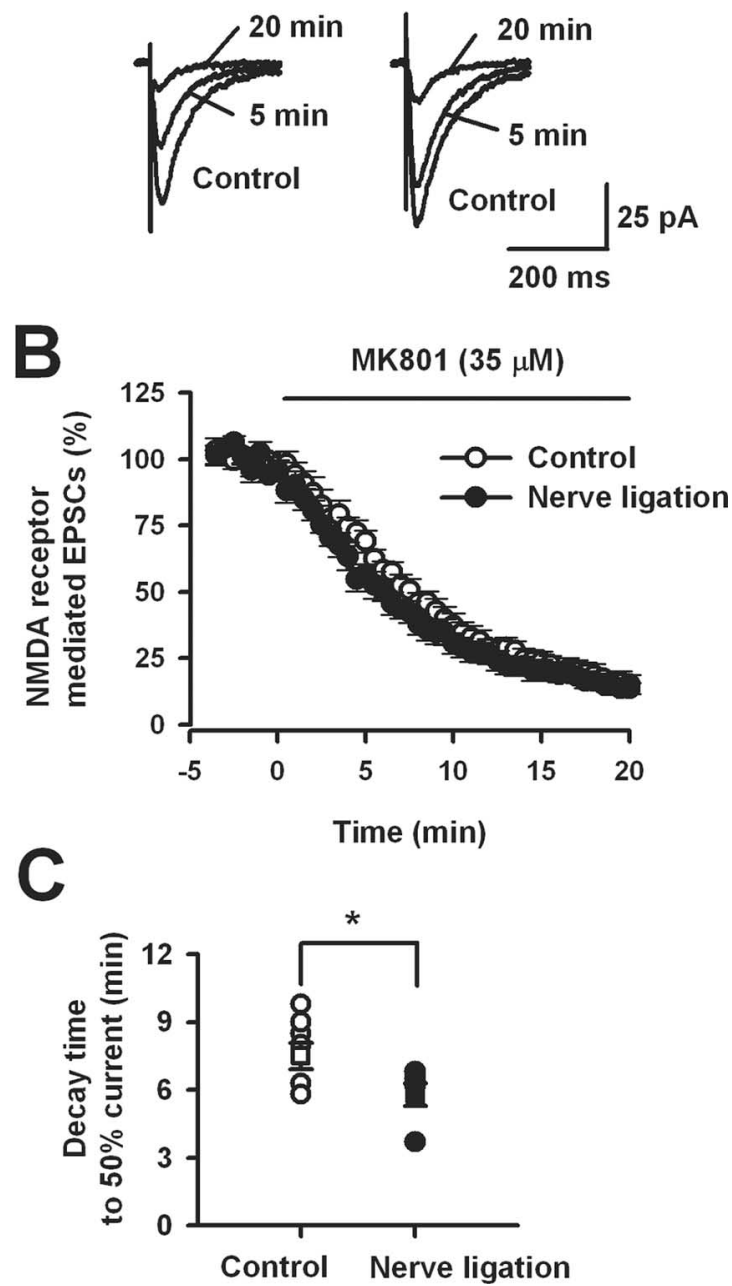

Figure 3. Faster MK-801 blockade of NMDA receptor-mediated EPSCs in mice with nerve ligation. $\boldsymbol{A}$, Representative traces show NMDA receptor-mediated EPSCs at 0,5 , and 20 min in the presence of MK-801 (35 $\mu \mathrm{M})$ in control and nerve-ligated mice. $\boldsymbol{B}$, Plot of time course of MK-801 blockade of NMDA receptor-mediated EPSCs in control mice and mice with nerve ligation. Open circles, From control mice ( $n=7$ neurons); filled circles, from mice with nerve ligation ( $n=8$ neurons). $C$, Individual and statistical data showed the decay time required for the peak amplitude of NMDA receptor-mediated EPSC to decrease to $50 \%$ of initial value in the presence of MK-801. Significantly faster time was observed in mice with nerve ligation $(n=8$ neurons) compared with control mice ( $n=7$ neurons). ${ }^{*} p<0.05$.

GluR1 and GluR2/3, the dominant subunits of AMPA receptors at central synapses (Geiger et al., 1995; Lambolez et al., 1996) after nerve injury. By Western blot, we found that there was no difference in the expression levels of both GluR1 and GluR2/3 receptors in ACC between the control mice and mice with nerve ligation $(p>0.05 ; n=6)$ (Fig. $4 A, B)$. These results indicate that the nerve injury has not altered the total protein expression levels of GluR1 and GluR2/3 subunits of AMPA receptors, and the enhanced synaptic transmission in the ACC may not be caused by the changes in the total protein levels of AMPA receptors.

The phosphorylation of GluR1 subunit of AMPA receptors is critical for synaptic expression of the receptors, their channel properties, and synaptic plasticity (Esteban et al., 2003; Lee et al., 2003; Vanhoose et al., 2006). We next tested the phosphorylation levels of GluR1 subunit at the PKA phosphorylation site (Ser 845) 
A

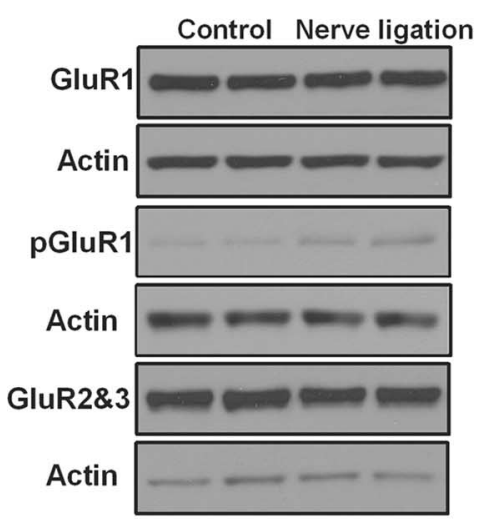

C

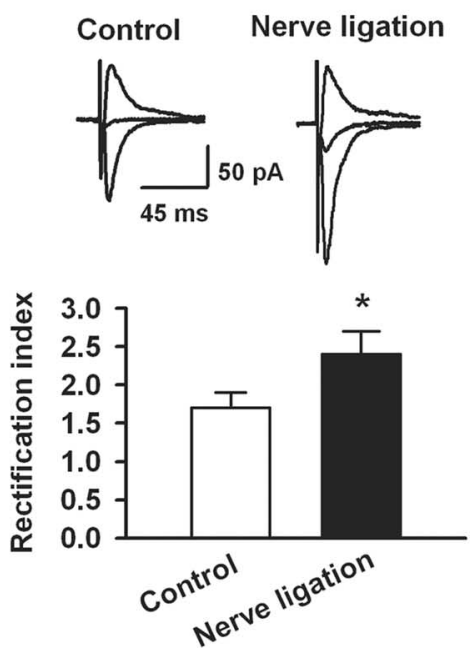

B

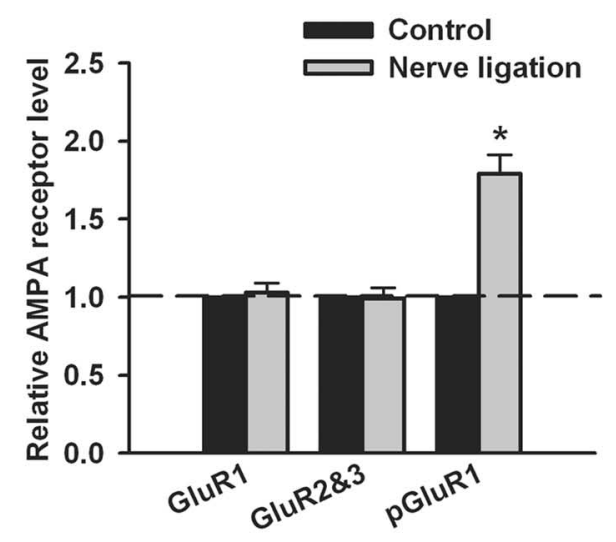

D

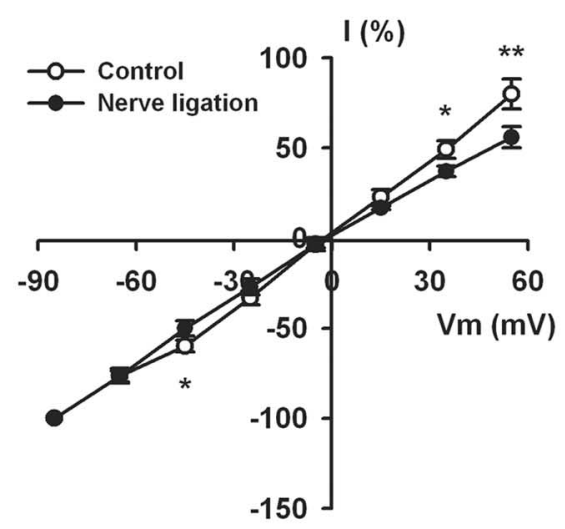

Figure 4. Altered phosphorylation of GluR1 and rectification index of AMPA receptor-mediated current in the ACC after nerve injury. $A$, Representative expression of GluR1 and phosphorylation of GluR1 and GluR2/3 by Western blot in the ACC from control and nerve-ligated mice. $\boldsymbol{B}$, Pooled data showing that phosphorylation of GluR1 was upregulated in mice with nerve ligation. $\boldsymbol{C}$, Representative traces of evoked AMPA receptor-mediated postsynaptic currents at $-65,-5$, and $+35 \mathrm{mV}$ holding potentials were recorded from one ACC neuron in control and nerve-ligated groups, respectively. Pooled data of rectification of AMPA receptor-mediated peak current show significant differences $\left({ }^{*} p<0.05\right)$. Open bars, Neurons from control mice $(n=12$ neurons); filled bars, neurons from mice with nerve ligation ( $n=18$ neurons). Rectification index $=$ (amplitude at $-65 \mathrm{mV}$ holding potential)/(amplitude at $+35 \mathrm{mV}$ holding potential). D, Mean /-V curve of AMPA EPSCs in ACC neurons from control and nerve-ligated mice. ${ }^{*} p<0.05 ;{ }^{* *} p<0.01$.

in the ACC of the mice with nerve ligation. We found that the phosphorylation levels of GluR1 were significantly increased in the ACC after nerve injury $(1.79 \pm 0.12$ times the control value; $p<0.01 ; n=6$ mice) (Fig. 4A,B). The data indicate that the nerve injury can increase the phosphorylation levels of GluR1 through the PKA signaling pathway.

\section{GluR1-mediated rectification}

AMPA receptors without GluR2 are $\mathrm{Ca}^{2+}$ permeable and inwardly rectifying (Geiger et al., 1995; Gu et al., 1996; Washburn et al., 1997). Inward rectification occurs by voltagedependent blockade by polyamines (Washburn and Dingledine, 1996). We tried to enhance inward rectification by increasing intracellular polyamines concentration. To identify whether there are inwardly rectifying properties of
AMPA receptors as a result of an alteration of their subunit composition in ACC neurons after nerve injury, we examined evoked AMPA receptormediated EPSCs at the holding potentials of $-65,-5$, and $+35 \mathrm{mV}$ in ACC neurons. We found that there was significant difference in the rectification of AMPA receptor-mediated transmission in the ACC between control ( $n=12$ neurons/5 mice) and nerve-ligated ( $n=18$ neurons/ 6 mice; $t$ test, $p<0.05$ ) (Fig. $4 C$ ) mice. Consistently, when the mean current-voltage $(I-V)$ relationship was plotted, less inward currents were found in ACC neurons from mice with nerve injury ( $n=18$ neurons/6 mice) compared with control mice $(n=12$ neurons/5 mice) (Fig. 4D). These results display that AMPA receptors in ACC neurons had an inward rectification property in neuropathic pain.

\section{Membrane GluR1 expression}

The trafficking of AMPA receptor subunits has been proposed to contribute to synaptic plasticity underlying hyperalgesia (Woolf and Salter, 2000). It has been reported that painful stimuli can recruit AMPA receptor GluR1 subunits to neuronal plasma membranes in the lumbar spinal cord (Galan et al., 2004). We next investigated the distribution of AMPA receptor subunits in the ACC after nerve ligation. We found that induction of neuropathic pain by nerve ligation was associated with an increase in the abundance of the GluR1 subunits in the membrane fraction and a corresponding decrease in the levels in the cytosolic fraction $(p<0.05$, compared with the control; $n=4$ mice) (Fig. 5A). In contrast, nerve ligation had no effect on the intracellular distribution of GluR2/3 subunits in ACC neurons $(p>0.05$, compared with the control; $n=4$ mice) (Fig. $5 B$ ). The data show that AMPA receptor GluR1 subunit is redistributed in ACC neurons as a result of nerve injury.

\section{ACC AMPA receptor and allodynia}

We have shown that peripheral nerve injury caused increased distribution of GluR1 and AMPA receptor-mediated synaptic transmission in the ACC. To directly address the critical role of AMPA receptor in neuropathic pain, we next performed experiment of intra-ACC infusion of CNQX (1 mM), a non-NMDA receptor antagonist, in mice after nerve injury and then tested for allodynia. The mechanical allodynia was tested on postsurgical days $1,3,5$, and 6 . On day 6 , mice were microinjected with CNQX $(n=6)$ (Fig. $5 C)$. We found that bilateral microinjection of CNQX significantly reduced the allodynia in both contralateral and ipsilateral sides, and the effect of CNQX disappeared when tested $2 \mathrm{~h}$ after injection $(n=6)$ (Fig. $5 C$ ). As a control, we found that CNQX did not affect the 50\% paw-withdrawal threshold 
when microinjected into the ACC of mice that had not undergone nerve ligation $(n=$ 3 mice; $p>0.05$ compared with baseline responses).

\section{Role of $\mathrm{AC} 1$ in presynaptic changes}

We have previously shown that $\mathrm{ACl}$ is critical for chronic pain. For example, in $A C 1^{-1-}$ mice, reduced chronic pain sensitization was found in inflammatory pain and neuropathic pain model (Wei et al., 2002). We want to know whether $A C 1$ is also involved in behavioral and synaptic changes in the current neuropathic pain model. We found that the mechanical allodynia is significantly reduced in both ipsilateral ( $p<0.05 ; n=4$ mice) (Fig. $6 A$ ) and contralateral ( $p<0.05 ; n=4$ mice) (Fig. $6 \mathrm{~A}$ ) sides of nerve injury in the knock-out mice. Moreover, after nerve injury, the $\mathrm{ACl}^{-1-}$ mice did not exhibit reduction in PPF of AMPA receptor-mediated EPSCs as shown by the wild-type mice after the nerve injury (control $A C 1^{-1-}, n=7$ neurons; $A C 1^{-1-}$ mice with nerve ligation, $n=9$ neurons; $p>0.05$ ) (Fig. 6B). We then tested the frequency and amplitude of mEPSCs in $\mathrm{ACl}^{-1-}$ mice after nerve injury. Although both frequency and amplitude of mEPSCs in ACC neurons were consistently increased in wild-type mice after nerve injury, no increase of mEPSC frequency or amplitude was observed in $A C 1^{-1-}$ mice [frequency in $A C 1^{-1-}$ control mice: $1.5 \pm$ $0.3 \mathrm{~Hz}, n=5$ neurons $/ 2$ mice; frequency in $A C 1^{-1-}$ mice with nerve ligation: $1.9 \pm 0.5$ $\mathrm{Hz}, n=11$ neurons $/ 4$ mice; $p>0.05$ (Fig. $6 C, D)$; amplitude in $\mathrm{ACl}^{-1-}$ control mice: $16.9 \pm 0.5 \mathrm{pA}, n=5$ neurons $/ 2$ mice; $A C 1^{-1-}$ amplitude in mice with nerve ligation: $15.4 \pm 1.7 \mathrm{pA}, n=11$ neurons $/ 4$ mice; $p>0.05$ (Fig. $6 C, D)]$. These results indicate that both presynaptic and postsynaptic enhancement of excitatory synaptic transmission in the $\mathrm{ACC}$ depend on $\mathrm{AC} 1$ in neuropathic pain.

\section{Role of $\mathrm{AC} 1$ in postsynaptic changes}

Next, Western blot analysis of basal levels of GluR1 and GluR2/3 proteins was performed on the ACC of control and nerve-ligated $A C 1^{-1-}$ mice. We found that the expression of GluR1 and GluR2/3 was not altered in the ACC of $A C 1^{-1-}$ mice compared with wild-type mice ( $p>0.05 ; n=4$ mice) (Fig. $7 A$ ). The data indicate that genetic deletion of $A C 1$ has not affected the expression of AMPA receptors in the ACC. We then tested the phosphorylation levels of GluR1 subunit in the ACC of $A C 1^{-1-}$ mice with neuropathic pain. We found that the basal levels of phosphorylated GluR1 were not changed in the ACC of $\mathrm{ACl}^{-1-}$ mice compared with wild-type mice. However, the increase of the phosphorylation levels of GluR1 induced by nerve injury was blocked in the ACC of $\mathrm{ACl}^{-1-}$ mice compared with wild-type mice (1.06 \pm 0.08 times increase in $A C 1^{-1-}$ mice vs $1.76 \pm 0.10$ times increase in wild-type mice; $p<0.01 ; n=4$ mice) (Fig. $7 B$ ). These results indicate that genetic deletion of $A C 1$ has not altered the basal levels of phosphorylated GluR1, and AC1 is involved in
B GluR2\&3
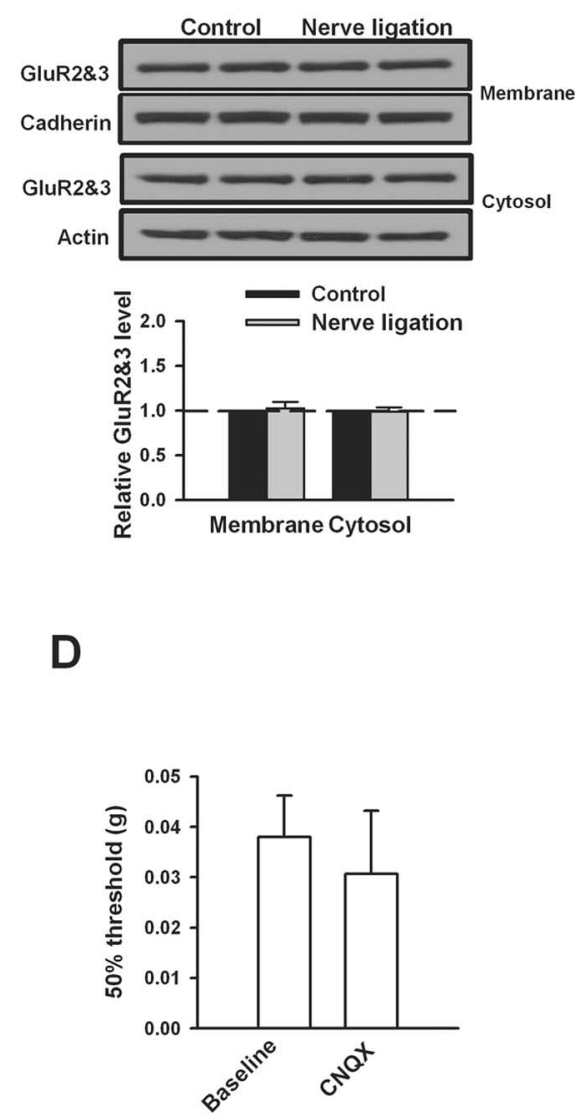

the phosphorylation of GluR1 receptors in the ACC during neuropathic pain.

In addition, we also examined the rectification of AMPA receptors in the ACC in $\mathrm{ACl}^{-1-}$ mice with internal spermine included in the pipette at holding potentials of $-65,-5$, and +35 $\mathrm{mV}$. There was no obvious difference in the rectification of AMPA receptor-mediated transmission in the ACC between $A C 1^{-1-}$ control ( $n=7$ neurons) and $A C 1^{-1-}$ mice with nerve ligation ( $n=9$ neurons) (two-way ANOVA, $p>0.05$ ) (Fig. 7C). This result indicates that postsynaptic GluR1 composition was not altered in $\mathrm{ACC}$ neurons in $A \mathrm{Cl}^{-1-}$ mice in neuropathic pain. Together, these results suggest that both presynaptic and postsynaptic $\mathrm{AC} 1$ might play key roles in regulating the increased excitatory synaptic transmission in the ACC after chronic nerve injury.

\section{Discussion}

The present study is built on our two previous observations. First, peripheral injuries trigger plastic changes in the ACC, including an array of activity-dependent immediate early genes, and enhanced synaptic responses (Wei et al., 1999; Wu et al., 2005; Zhuo, 2007). No identification of presynaptic versus postsynaptic mechanisms have been performed in the ACC in case of nerve 
A

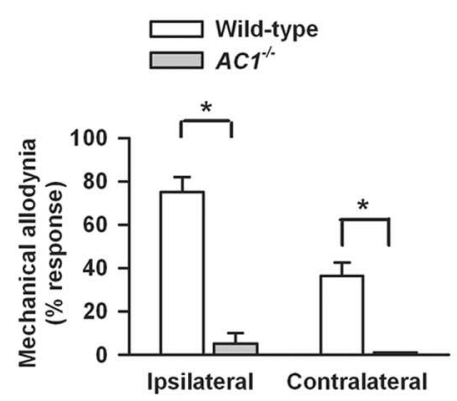

C

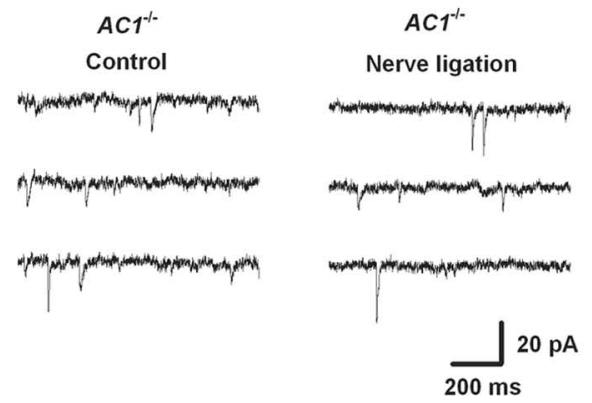

B

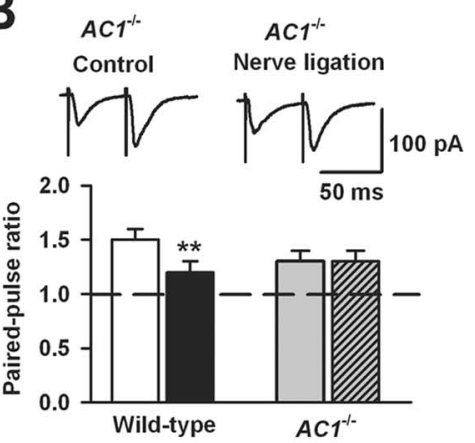

D

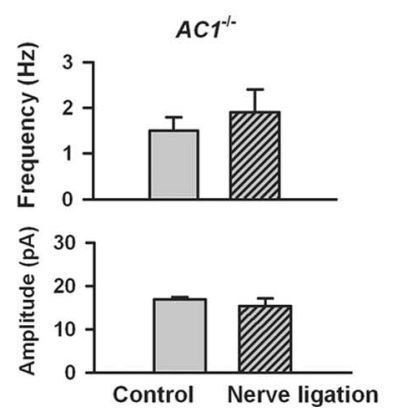

Figure 6. Paired-pulse facilitation in $\mathrm{ACC}$ neurons in $\mathrm{AC}^{-/-}$mice with nerve ligation. $A$, Reduced mechanical allodynia in $A C 1^{-1-}$ mice with nerve ligation ( $n=4$ mice). ${ }^{*} p<0.05$. $B$, The reduction in PPF of AMPA receptor-mediated EPSCs as shown by the wild-type mice after nerve injury was abolished in $A C 1^{-1-}$ mice after nerve injury. ${ }^{* *} p<0.01$. Insets, Representative traces of PPF with an interval of $50 \mathrm{~ms}$ recorded in the ACC. $C$, $\mathrm{mEPSCS}$ recorded in $\mathrm{ACC}$ neurons from $\mathrm{AC1^{-/- }}$ mice with nerve ligation. Shown are representative $\mathrm{mEPSCs}$ recorded in the $\mathrm{ACC}$ neuron in slices from $\mathrm{AC}^{-1-}$ control mice (left) and mice with nerve injury (right) at a holding potential of $-70 \mathrm{mV}$. D, Summary plots of $\mathrm{mEPSC}$ data. Average values of $\mathrm{mEPSC}$ parameters are shown. Shown are mean peak frequency (top) and amplitude (bottom) in $\mathrm{ACl}^{-1-}$ control mice ( $n=5$ neurons) and $\mathrm{AC}^{-1-}$ mice with nerve ligation ( $n=11$ neurons; $p>0.05$ ).

injury (Wu et al., 2005; Zhao et al., 2006). Second, AC1 and AC8, two major forms of calcium-stimulated ACs, are critical for chronic pain in animal models including neuropathic pain (Wei et al., 2002; Vadakkan et al., 2006). No selective or relatively selective $\mathrm{AC} 1$ inhibitor has been reported, to our knowledge. Our current findings thus provide the evidence of synaptic mechanism for neuronal plastic changes in the ACC after nerve injury, namely presynaptic enhancement of glutamate release probability, as well as postsynaptic enhancement of AMPA receptormediated responses.

\section{Presynaptic and postsynaptic changes in LTP and chronic pain}

Both presynaptic and postsynaptic changes have been found to contribute to LTP (Malgaroli and Tsien, 1992; Bolshakov and Siegelbaum, 1995; Nicoll and Malenka, 1995; Kandel, 2001; Malinow and Malenka, 2002; Nicoll and Schmitz, 2005). Depending on the central regions of the brain and experimental conditions, presynaptic enhancement of glutamate release or postsynaptic enhancement of AMPA receptor-mediated responses can be responsible for the expression of LTP. For example, in the CA3 region of hippocampus, it has been reported that LTP is presynaptically expressed and requires the activity of AC1 (Nicoll and Schmitz, 2005). In the CA1 region of the hippocampus, presynaptic and postsynaptic mechanisms for LTP have been hotly debated, including the postsynaptic AMPA receptor trafficking and insertion, and may also require retrograde messengers under certain conditions (see reviews above). Hippocampus and hippocampus-related limbic structures are proposed to be critical for spatial learning and memory (Kandel, 2001). Unlike the hippocampus, the ACC is critical for affective cognitive functions, including decision making, trace memory, attention, and persistent pain (Zhuo, 2007). ACC LTP can be induced by different induction protocols. Our recent pharmacological and genetic approaches have found that AMPA GluR1 receptor is critical for the expression of LTP (Toyoda et al., 2007). In the present study, in ACC slices of neuropathic pain mice, we found that both presynaptic and postsynaptic glutamate transmission are undergoing long-term potentiation. Presynaptic enhancement, as evaluated by three different methods, was observed after the injury, indicating the presynaptic enhancement of glutamate releases. At postsynaptic site, both electrophysiological and biochemical data suggest that AMPA receptor GluR1-mediated responses are enhanced. Although our studies cannot draw any conclusion of possible insertion for GluR1 receptors, electrophysiological data do suggest this possibility. Our results thus provide the evidence for pain-related both presynaptic and postsynaptic enhancement in the ACC, and stimulation-induced LTP in normal brain slices can be used to mimic or model postsynaptic mechanisms of injury-induced changes (Zhao et al., 2005).

\section{Calcium-stimulated AC1 in synaptic plasticity and pain}

Previous studies have shown that ACl mRNA was highly expressed in the ACC and that AC1 contributed to behavioral nociceptive responses to nerve injury and inflammation (Wei et al., 2002). In mice lacking $A C 1$, we found that chronic pain, including neuropathic pain and inflammation-related allodynia, is significantly reduced, whereas acute pain in response to noxious thermal or mechanical stimuli remain intact (Wei et al., 2002). These results suggest that $\mathrm{AC} 1$ is selectively involved in persistent or chronic pain. In neurons, it has been proposed that AC1 couples NMDA receptor-induced cytosolic $\mathrm{Ca}^{2+}$ elevation to cAMP signaling pathways (Chetkovich and Sweatt, 1993; Wong et al., 1999). Because activation of NMDA receptor contributes to persistent/chronic pain (Wu et al., 2005), it is likely that $\mathrm{ACl}$ can act downstream from the NMDA receptor, and thus contribute to chronic pain (Zhuo, 2008). The molecular mechanisms may involve the activation of PKA pathway after AC1 activation, and the following phosphorylation and the recruitment of GluR1 to membrane. The similar mechanism for GluR1 trafficking has been reported in hippocampus (Lee et al., 2003; Derkach et al., 2007). Therefore, AC1 in the ACC is an attractive candidate serving for the initiation of GluR1 trafficking and chronic pain.

In the present study, we found that both presynaptic enhancements and postsynaptic changes in AMPA receptor-mediated responses were blocked in AC1 knock-out mice, indicating that $\mathrm{AC} 1$ may contribute both presynaptically and postsynaptically to 

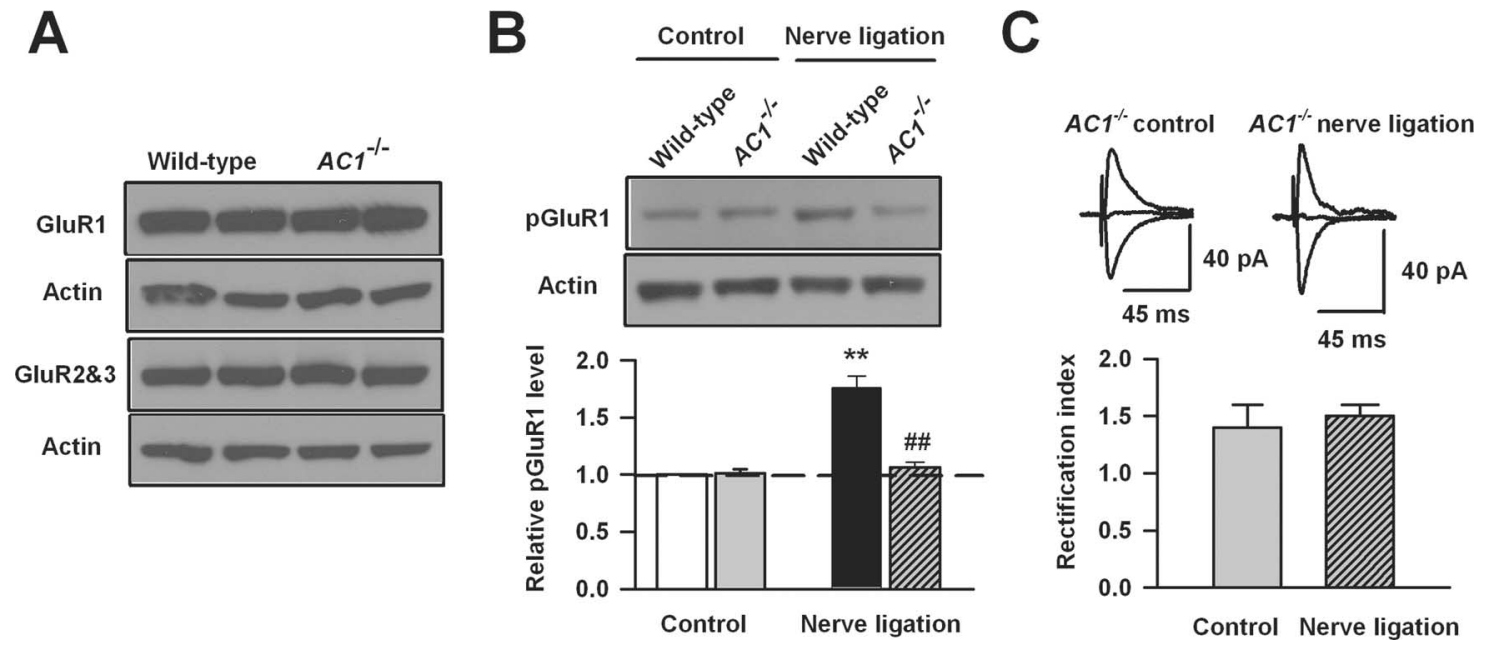

Figure 7. Expression of GluR1 and rectification index of AMPA receptor-mediated currents in ACC neurons from $A C 1^{-1-}$ mice with nerve ligation. $A$, Representative Western blot of GluR1 and GluR2/3 in the ACC from wild-type and $A C 1^{-1-}$ mice with nerve ligation. $B$, Representative Western blot and corresponding quantitation of the phosphorylation of GluR1 at Ser845 in the $A C C$ from wild-type mice $(n=6)$, wild-type mice with nerve ligation $(n=6), A C 1^{-1-}$ control mice $(n=4)$, and $A C 1^{-1-}$ mice with nerve ligation $(n=4)$. The phosphorylation levels of GluR1 were significantly increased in the ACC after nerve injury $\left({ }^{* *} p<0.01 ; n=6\right)$ in wild-type mice. The increase of the phosphorylation levels of GluR1 induced by nerve injury was blocked in the ACC of $A C 1^{-I-}$ mice compared with wild-type mice ( $\left.{ }^{\# \#} p<0.01 ; n=4\right)$. C, Representative traces and pooled data of rectification index of AMPA receptor-mediated current in the ACC from $A C 1^{-I-}$ control and $A C 1^{-1-}$ mice with nerve ligation.

injury-induced plastic changes in the ACC. In fact, the stimulation of AC1 is critical for mossy fiber LTP (Bolshakov et al., 1997; Villacres et al., 1998). Because basic properties of synapses are not affected, including paired-pulse facilitation, AMPA receptormediated responses, and NMDA receptor-mediated responses in $\mathrm{AC} 1$ knock-out mice, we believe that the involvement of $\mathrm{AC} 1$ is activity dependent, rather than other nonselective side effects. In addition to cortical region, $\mathrm{AC} 1$ is also likely involved in spinal cord plasticity. In previous studies, we have demonstrated that genetic deletion of AC1 inhibits spinal cord LTP induced by pairing training protocol and synaptic facilitation induced by coapplication of forskolin and serotonin (Wang and Zhuo, 2002; Wei et al., 2006). Considering the increasing evidence of spinal LTP and descending facilitation in chronic pain, it is conceivable that spinal AC1 mechanisms may also contribute to allodynia.

\section{References}

Balasubramanyan S, Stemkowski PL, Stebbing MJ, Smith PA (2006) Sciatic chronic constriction injury produces cell-type-specific changes in the electrophysiological properties of rat substantia gelatinosa neurons. J Neurophysiol 96:579-590.

Blair HT, Schafe GE, Bauer EP, Rodrigues SM, LeDoux JE (2001) Synaptic plasticity in the lateral amygdala: a cellular hypothesis of fear conditioning. Learn Mem 8:229-242.

Bliss TV, Collingridge GL (1993) A synaptic model of memory: long-term potentiation in the hippocampus. Nature 361:31-39.

Bolshakov VY, Siegelbaum SA (1995) Regulation of hippocampal transmitter release during development and long-term potentiation. Science 269:1730-1734.

Bolshakov VY, Golan H, Kandel ER, Siegelbaum SA (1997) Recruitment of new sites of synaptic transmission during the cAMP-dependent late phase of LTP at CA3-CA1 synapses in the hippocampus. Neuron 19:635-651.

Boucher TJ, McMahon SB (2001) Neurotrophic factors and neuropathic pain. Curr Opin Pharmacol 1:66-72.

Buonomano DV, Merzenich MM (1998) Cortical plasticity: from synapses to maps. Annu Rev Neurosci 21:149-186.

Casey KL (1999) Forebrain mechanisms of nociception and pain: analysis through imaging. Proc Natl Acad Sci U S A 96:7668-7674.

Chetkovich DM, Sweatt JD (1993) nMDA receptor activation increases cyclic AMP in area CA1 of the hippocampus via calcium/calmodulin stimulation of adenylyl cyclase. J Neurochem 61:1933-1942.

Coull JA, Boudreau D, Bachand K, Prescott SA, Nault F, Sík A, De Koninck P,
De Koninck Y (2003) Trans-synaptic shift in anion gradient in spinal lamina I neurons as a mechanism of neuropathic pain. Nature 424:938-942.

Coull JA, Beggs S, Boudreau D, Boivin D, Tsuda M, Inoue K, Gravel C, Salter MW, De Koninck Y (2005) BDNF from microglia causes the shift in neuronal anion gradient underlying neuropathic pain. Nature 438:1017-1021.

Davis M, Rainnie D, Cassell M (1994) Neurotransmission in the rat amygdala related to fear and anxiety. Trends Neurosci 17:208-214.

Derkach VA, Oh MC, Guire ES, Soderling TR (2007) Regulatory mechanisms of AMPA receptors in synaptic plasticity. Nat Rev Neurosci 8:101-113.

Eisenberger NI, Lieberman MD, Williams KD (2003) Does rejection hurt? An FMRI study of social exclusion. Science 302:290-292.

Esteban JA, Shi SH, Wilson C, Nuriya M, Huganir RL, Malinow R (2003) PKA phosphorylation of AMPA receptor subunits controls synaptic trafficking underlying plasticity. Nat Neurosci 6:136-143.

Foster TC, McNaughton BL (1991) Long-term enhancement of CA1 synaptic transmission is due to increased quantal size, not quantal content. Hippocampus 1:79-91.

Galan A, Laird JM, Cervero F (2004) In vivo recruitment by painful stimuli of AMPA receptor subunits to the plasma membrane of spinal cord neurons. Pain 112:315-323.

Geiger JR, Melcher T, Koh DS, Sakmann B, Seeburg PH, Jonas P, Monyer H (1995) Relative abundance of subunit mRNAs determines gating and $\mathrm{Ca} 2+$ permeability of AMPA receptors in principal neurons and interneurons in rat CNS. Neuron 15:193-204.

Gu JG, Albuquerque C, Lee CJ, MacDermott AB (1996) Synaptic strengthening through activation of $\mathrm{Ca} 2+$-permeable AMPA receptors. Nature 381:793-796.

Hessler NA, Shirke AM, Malinow R (1993) The probability of transmitter release at a mammalian central synapse. Nature 366:569-572.

Hollmann M, Heinemann S (1994) Cloned glutamate receptors. Annu Rev Neurosci 17:31-108.

Hutchison WD, Davis KD, Lozano AM, Tasker RR, Dostrovsky JO (1999) Pain-related neurons in the human cingulate cortex. Nat Neurosci 2:403-405.

Ikeda H, Heinke B, Ruscheweyh R, Sandkühler J (2003) Synaptic plasticity in spinal lamina I projection neurons that mediate hyperalgesia. Science 299:1237-1240.

Ikeda H, Stark J, Fischer H, Wagner M, Drdla R, Jäger T, Sandkühler J (2006) Synaptic amplifier of inflammatory pain in the spinal dorsal horn. Science 312:1659-1662.

Johansen JP, Fields HL, Manning BH (2001) The affective component of 
pain in rodents: direct evidence for a contribution of the anterior cingulate cortex. Proc Natl Acad Sci U S A 98:8077-8082.

Kaas JH (1991) Plasticity of sensory and motor maps in adult mammals. Annu Rev Neurosci 14:137-167.

Kandel ER (2001) The molecular biology of memory storage: a dialogue between genes and synapses. Science 294:1030-1038.

Kohno T, Moore KA, Baba H, Woolf CJ (2003) Peripheral nerve injury alters excitatory synaptic transmission in lamina II of the rat dorsal horn. J Physiol 548:131-138.

Koyama T, Tanaka YZ, Mikami A (1998) Nociceptive neurons in the macaque anterior cingulate activate during anticipation of pain. Neuroreport 9:2663-2667.

Koyama T, Kato K, Mikami A (2000) During pain-avoidance neurons activated in the macaque anterior cingulate and caudate. Neurosci Lett 283:17-20.

Lambolez B, Ropert N, Perrais D, Rossier J, Hestrin S (1996) Correlation between kinetics and RNA splicing of alpha-amino-3-hydroxy-5methylisoxazole-4-propionic acid receptors in neocortical neurons. Proc Natl Acad Sci U S A 93:1797-1802.

LeDoux J (2003) The emotional brain, fear, and the amygdala. Cell Mol Neurobiol 23:727-738.

Lee DE, Kim SJ, Zhuo M (1999) Comparison of behavioral responses to noxious cold and heat in mice. Brain Res 845:117-121.

Lee HK, Takamiya K, Han JS, Man H, Kim CH, Rumbaugh G, Yu S, Ding L, He C, Petralia RS, Wenthold RJ, Gallagher M, Huganir RL (2003) Phosphorylation of the AMPA receptor GluR1 subunit is required for synaptic plasticity and retention of spatial memory. Cell 112:631-643.

Malenka RC, Nicoll RA (1997) Learning and memory. Never fear, LTP is hear. Nature 390:552-553.

Malgaroli A, Tsien RW (1992) Glutamate-induced long-term potentiation of the frequency of miniature synaptic currents in cultured hippocampal neurons. Nature 357:134-139.

Malinow R, Malenka RC (2002) AMPA receptor trafficking and synaptic plasticity. Annu Rev Neurosci 25:103-126.

McKernan MG, Shinnick-Gallagher P (1997) Fear conditioning induces a lasting potentiation of synaptic currents in vitro. Nature 390:607-611.

Morozov A, Muzzio IA, Bourtchouladze R, Van-Strien N, Lapidus K, Yin D, Winder DG, Adams JP, Sweatt JD, Kandel ER (2003) Rap1 couples cAMP signaling to a distinct pool of p42/44MAPK regulating excitability, synaptic plasticity, learning, and memory. Neuron 39:309-325.

Nassar MA, Baker MD, Levato A, Ingram R, Mallucci G, McMahon SB, Wood JN (2006) Nerve injury induces robust allodynia and ectopic discharges in Nav1.3 null mutant mice. Mol Pain 2:33.

Nicoll RA, Malenka RC (1995) Contrasting properties of two forms of longterm potentiation in the hippocampus. Nature 377:115-118.

Nicoll RA, Schmitz D (2005) Synaptic plasticity at hippocampal mossy fibre synapses. Nat Rev Neurosci 6:863-876.

Rainville P, Duncan GH, Price DD, Carrier B, Bushnell MC (1997) Pain affect encoded in human anterior cingulate but not somatosensory cortex. Science 277:968-971.

Rainville P, Bushnell MC, Duncan GH (2001) Representation of acute and persistent pain in the human CNS: potential implications for chemical intolerance. Ann N Y Acad Sci 933:130-141.

Rumpel S, LeDoux J, Zador A, Malinow R (2005) Postsynaptic receptor trafficking underlying a form of associative learning. Science 308:83-88.

Sandkühler J (2007) Understanding LTP in pain pathways. Mol Pain 3:9.

Sikes RW, Vogt BA (1992) Nociceptive neurons in area 24 of rabbit cingulate cortex. J Neurophysiol 68:1720-1732.

Sommer B, Köhler M, Sprengel R, Seeburg PH (1991) RNA editing in brain controls a determinant of ion flow in glutamate-gated channels. Cell 67:11-19.

Talbot JD, Marrett S, Evans AC, Meyer E, Bushnell MC, Duncan GH (1991) Multiple representations of pain in human cerebral cortex. Science 251:1355-1358

Toyoda H, Wu LJ, Zhao MG, Xu H, Zhuo M (2007) Time-dependent postsynaptic AMPA GluR1 receptor recruitment in the cingulate synaptic potentiation. Dev Neurobiol 67:498-509.

Tsvetkov E, Carlezon WA, Benes FM, Kandel ER, Bolshakov VY (2002) Fear conditioning occludes LTP-induced presynaptic enhancement of synaptic transmission in the cortical pathway to the lateral amygdala. Neuron 34:289-300.

Tsvetkov E, Shin RM, Bolshakov VY (2004) Glutamate uptake determines pathway specificity of long-term potentiation in the neural circuitry of fear conditioning. Neuron 41:139-151.

Vadakkan KI, Jia YH, Zhuo M (2005) A behavioral model of neuropathic pain induced by ligation of the common peroneal nerve in mice. J Pain 6:747-756.

Vadakkan KI, Wang H, Ko SW, Zastepa E, Petrovic MJ, Sluka KA, Zhuo M (2006) Genetic reduction of chronic muscle pain in mice lacking calcium/calmodulin-stimulated adenylyl cyclases. Mol Pain 2:7.

Vanhoose AM, Clements JM, Winder DG (2006) Novel blockade of protein kinase A-mediated phosphorylation of AMPA receptors. J Neurosci 26:1138-1145.

Villacres EC, Wong ST, Chavkin C, Storm DR (1998) Type I adenylyl cyclase mutant mice have impaired mossy fiber long-term potentiation. J Neurosci 18:3186-3194.

Wang GD, Zhuo M (2002) Synergistic enhancement of glutamate-mediated responses by serotonin and forskolin in adult mouse spinal dorsal horn neurons. J Neurophysiol 87:732-739.

Wang H, Gong B, Vadakkan KI, Toyoda H, Kaang BK, Zhuo M (2007) Genetic evidence for adenylyl cyclase 1 as a target for preventing neuronal excitotoxicity mediated by $\mathrm{N}$-methyl-D-aspartate receptors. J Biol Chem 282:1507-1517.

Washburn MS, Dingledine R (1996) Block of alpha-amino-3-hydroxy-5methyl-4-isoxazolepropionic acid (AMPA) receptors by polyamines and polyamine toxins. J Pharmacol Exp Ther 278:669-678.

Washburn MS, Numberger M, Zhang S, Dingledine R (1997) Differential dependence on GluR2 expression of three characteristic features of AMPA receptors. J Neurosci 17:9393-9406.

Wei F, Li P, Zhuo M (1999) Loss of synaptic depression in mammalian anterior cingulate cortex after amputation. J Neurosci 19:9346-9354.

Wei F, Wang GD, Kerchner GA, Kim SJ, Xu HM, Chen ZF, Zhuo M (2001) Genetic enhancement of inflammatory pain by forebrain NR2B overexpression. Nat Neurosci 4:164-169.

Wei F, Qiu CS, Kim SJ, Muglia L, Maas JW, Pineda VV, Xu HM, Chen ZF, Storm DR, Muglia LJ, Zhuo M (2002) Genetic elimination of behavioral sensitization in mice lacking calmodulin-stimulated adenylyl cyclases. Neuron 36:713-726.

Wei F, Vadakkan KI, Toyoda H, Wu LJ, Zhao MG, Xu H, Shum FW, Jia YH, Zhuo M (2006) Calcium calmodulin-stimulated adenylyl cyclases contribute to activation of extracellular signal-regulated kinase in spinal dorsal horn neurons in adult rats and mice. J Neurosci 26:851-861.

Weisskopf MG, Nicoll RA (1995) Presynaptic changes during mossy fibre LTP revealed by NMDA receptor-mediated synaptic responses. Nature 376:256-259.

Wong ST, Athos J, Figueroa XA, Pineda VV, Schaefer ML, Chavkin CC, Muglia LJ, Storm DR (1999) Calcium-stimulated adenylyl cyclase activity is critical for hippocampus-dependent long-term memory and late phase LTP. Neuron 23:787-798.

Woolf CJ, Salter MW (2000) Neuronal plasticity: increasing the gain in pain. Science 288:1765-1769.

Wu LJ, Toyoda H, Zhao MG, Lee YS, Tang J, Ko SW, Jia YH, Shum FW, Zerbinatti CV, Bu G, Wei F, Xu TL, Muglia LJ, Chen ZF, Auberson YP, Kaang BK, Zhuo M (2005) Upregulation of forebrain NMDA NR2B receptors contributes to behavioral sensitization after inflammation. J Neurosci 25:11107-11116.

Yamamura H, Iwata K, Tsuboi Y, Toda K, Kitajima K, Shimizu N, Nomura H, Hibiya J, Fujita S, Sumino R (1996) Morphological and electrophysiological properties of ACCx nociceptive neurons in rats. Brain Res 735:83-92.

Zhao MG, Toyoda H, Lee YS, Wu LJ, Ko SW, Zhang XH, Jia Y, Shum F, Xu H, Li BM, Kaang BK, Zhuo M (2005) Roles of NMDA NR2B subtype receptor in prefrontal long-term potentiation and contextual fear memory. Neuron 47:859-872.

Zhao MG, Ko SW, Wu LJ, Toyoda H, Xu H, Quan J, Li J, Jia Y, Ren M, Xu ZC, Zhuo M (2006) Enhanced presynaptic neurotransmitter release in the anterior cingulate cortex of mice with chronic pain. J Neurosci 26:8923-8930.

Zhuo M (2006) Molecular mechanisms of pain in the anterior cingulate cortex. J Neurosci Res 84:927-933.

Zhuo M (2007) Neuronal mechanism for neuropathic pain. Mol Pain 3:14. Zhuo M (2008) Cortical excitation and chronic pain. Trends Neurosci 31: 199-207. 